Laser Chem. 1988, Vol. 9, pp. 171-193

(C) 1988 Harwood Academic Publishers GmbH

Photocopying permitted by license only

Reprints available directly from the Publisher

Printed in the United Kingdom

\title{
Laser Stimulation and Observation of Simple Gas Phase Radical Reactions
}

\section{J. WOLFRUM}

\begin{abstract}
Physikalisch-Chemisches Institut, Universität Heidelberg, Im Neuenheimer Feld 253, D-6900 Heidelberg, FRG
\end{abstract}

(Received January 19, 1988; in final form March 29, 1988)

Experiments on the effect of selective vibrational, translational and orientations excitation of reactants in bimolecular reactions can give important insights into the microscopic dynamics of elementary chemical reactions. The information obtained in such experiments can be compared with the results of theoretical calculations of the reaction dynamics based on ab initio potential energy surfaces and is also of basic interest to improve the kinetic data used in detailed chemical kinetic modelling.

Rotational and vibrational energy transfer between $\mathrm{H}_{2}$ and $\mathrm{H}_{0}$ has been studied directly using Raman excitation combined with time resolved CARS spectroscopy. The competition between reactive and inelastic channels was investigated for reactions of atoms with vibrationally excited $\mathrm{H}_{2}$ and $\mathrm{HCl}$ molecules. Selective vibrational excitation was achieved by using infrared laser or Raman-pumping. The reaction products were detected by time resolved atomic line resonance absorption mass-spectrometry and CARS-spectroscopy. In some cases information on the contributions of adiabatic and non-adiabatic reactive pathways could be obtained. The reaction $\mathrm{H}+\mathrm{O}_{2} \rightarrow \mathrm{OH}+\mathrm{O}$ has been studied using translationally hot $\mathrm{H}$ atoms at various energies. Absolute total reactive cross-sections, nascent rotational state distributions and information on the distribution of orientations of the $\mathrm{OH}$ angular momentum vector using polarized dissociation and analysis laser sources have been obtained.

KEY WORDS: Energy transfer, reactive collisions, hot $\mathrm{H}$ atoms.

\section{INTRODUCTION}

Reactions of free atoms and radicals in the gas phase have attracted numerous investigators during this century mainly for two reasons:

Such reactions are among the simplest of chemical processes. They 
offer favorable conditions for a quantitative theoretical treatment and demonstrate many properties typical of neutral particle reactions. These properties include not only the classical Arrhenius parameters, but also information about the "activated complex" and the "rearrangement" of the reactants during the reactive process, the probabilities of various reaction pathways, the distribution of the reaction energy over the products, and the influence of specific excitation of the reacting particles.

On the other hand, the practical use of the fast reactions of atoms and free radicals in combustion processes is one of the oldest of our chemical techniques. Since the classical investigations of Bodenstein ${ }^{1}$ and Nernst ${ }^{2}$ it has been well known that even the simple combustion of hydrogen does not actually take place in the form given by the stoichiometric relation. Instead, the reaction proceeds through a set of atom and radical reactions. In recent years it has become increasingly clear that the rapid expansion of the use of combustion processes has reached the point that the natural atmosphere is being considerably affected. A thorough knowledge of the elementary steps taking place in explosion and combustion processes is therefore clearly needed. Furthermore, the reactions of free atoms and radicals also play an important part in many photochemically and radiation-initiated processes such as occur inthe lower and the upper atmosphere, in chemical lasers, and in many industrial applications.

The experimental possibilities for studying the dynamics of elementary gas phase reactions in microscopic detail have expanded dramatically in recent years as a result of the development of various laser sources. The tunability, polarization, monochromaticity, collimation, coherence and short pulse duration of laser light in a wide spectral range can be used to obtain microscopic information on the molecular course of transferring energy or breaking and reforming chemical bonds. Careful comparison of these experimental results with theoretical predictions can test potential energy surfaces obtained by ab initio methods and dynamical simulations using quantum and quasiclassical methods.

\section{ROTATIONAL AND VIBRATIONAL ENERGY TRANSFER FROM $H_{2}\left(v^{\prime \prime}=1, j^{\prime \prime}=1\right)$ MOLECULES}

Energy transfer in collisions of hydrogen molecules with atoms and 
other molecules has been the subject of intensive experimental and theoretical investigations using crossed molecular beam experiments. ${ }^{3}$ Due to the lack of a dipole moment and an electronic absorption spectrum in the vacuum ultraviolet state-selective studies using spectroscopic methods were difficult to perform for a long time, before laser methods became available. Figure 1 shows the excitation and detection scheme of a laser experiment for energy transfer studies of hydrogen molecules. Stimulated Raman pumping is employed to populate $\mathrm{H}_{2}\left(v^{\prime \prime}=1, J^{\prime \prime}=1\right)$ selectively in the electronic ground state of hydrogen within a $10 \mathrm{~ns}$ laser pulse. The time-dependent populations in rotational and vibrational levels in hydrogen and isotopic modifications can be probed by coherent anti-Stokes Raman spectroscopy (CARS). Figure 2 shows schematically the experimental arrangement. ${ }^{4}$ Fifty per cent of the energy output of a linearly polarized frequency-doubled Nd:YAG laser (Quanta Ray DCR1A, at $532 \mathrm{~nm}$ ) is focussed into a Raman cell containing a hydrogen-helium mixture with partial pressures of 20 bar and 10 bar respectively. The helium is used to reduce the pressure-dependent line shift of the Stokes line. Stimulated Stokes Raman radiation is generated in forward and backward directions. Due to the phase conjugation effect in stimulated
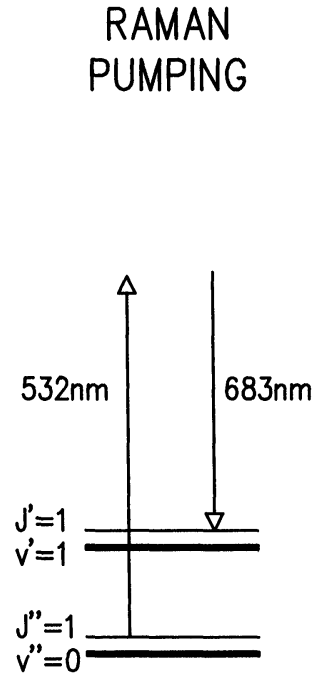
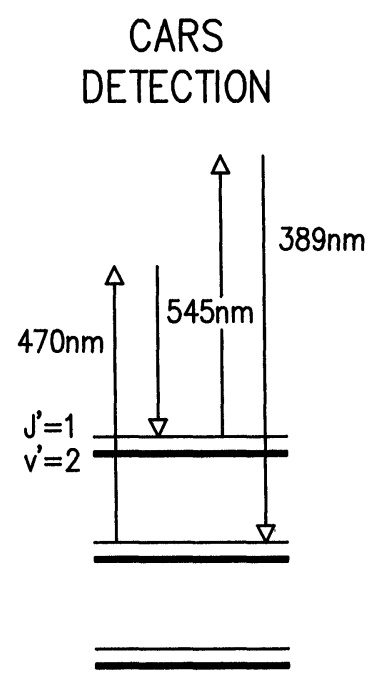

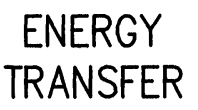

Figure 1 Excitation and detection scheme for energy transfer studies of hydrogen molecules.

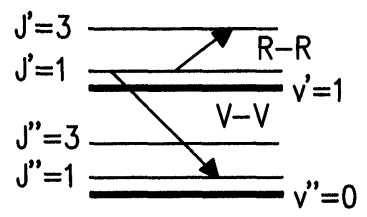




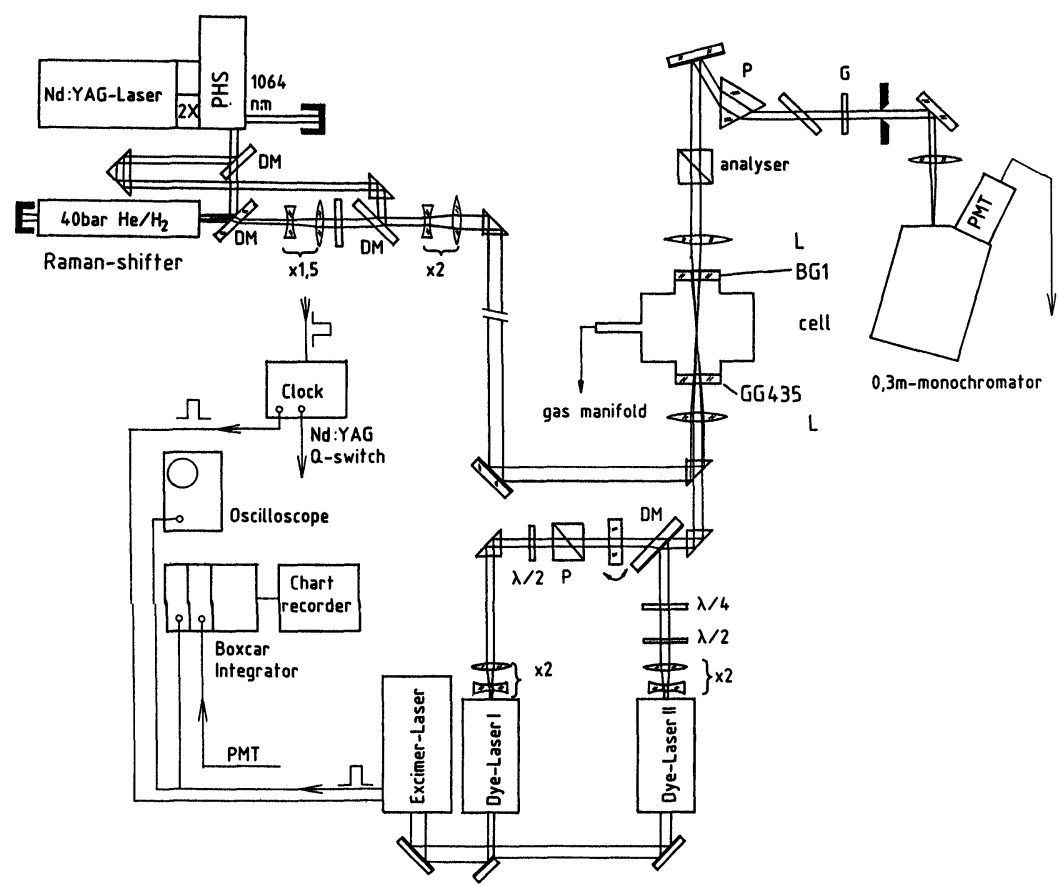

Figure 2 Schematic diagram for the experimental arrangement for CARS detection of Raman-excited hydrogen molecules.

Raman-scattering, the backward beam displayed a more homogeneous intensity distribution over the beam cross section and a smaller divergence than the forward scattered beam. Both beams are focussed collinearly into the centre of the reaction cell with a beam waist of about $200 \mu \mathrm{m}$ diameter for fundamental and Stokes beams. With this arrangement, the rotational relaxation in pure $\mathrm{H}_{2}$ and $\mathrm{H}_{2}$ mixtures can be studied. The time dependent CARS signals of $\mathrm{H}_{2}$ $(v=1, J=1)$ and $\mathrm{H}_{2}(v=1, J=3)$ are seen in Figure $3 \mathrm{a}, \mathrm{b}$. The solid line is a simulation based on a "Multi Step Kinetics with Multi Species Transport Model Program."5

The rate constants obtained from this modelling for the relaxation processes

$$
\mathrm{H}_{2}(v=1, J=1) \stackrel{k_{13}}{\stackrel{k_{31}}{\rightleftharpoons}} \mathrm{H}_{2}(v=1, J=3)
$$

of $k_{13}=2.2 \times 10^{-12} \mathrm{~cm}^{3} / \mathrm{s}$ and $k_{31}=1.4 \times 10^{-11} \mathrm{~cm}^{3} / \mathrm{s}$ in good 


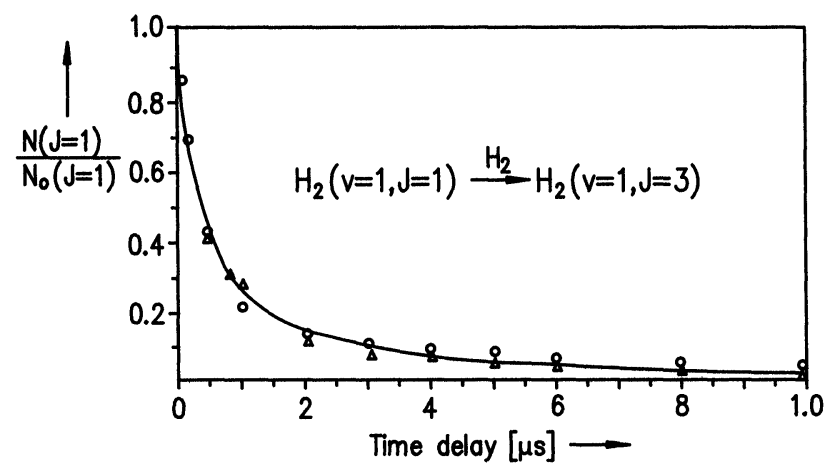

(a)

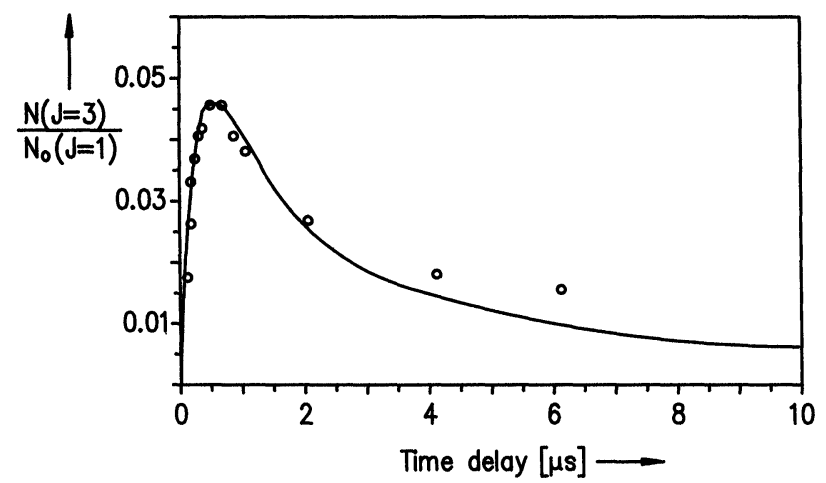

(b)

Figure 3 Temporal variation of the CARS signals from $\mathrm{H}_{2}\left(v^{\prime \prime}=1, J^{\prime \prime}=1\right.$ (a); and $\mathrm{H}_{2}$ $\left(v^{\prime \prime}=1, J^{\prime \prime}=3\right)(\mathrm{b})$; due to rotational energy transfer and diffusion processes. Solid lines: simulations.

agreement with measurements using LIF-Spectroscopy in the VUV spectral region for $\mathrm{H}_{2}$ detection. ${ }^{6}$

The rotational energy transfer rates of $\mathrm{H}_{2}(v=1)$ molecules are about an order magnitude higher than similar rates in the vibrational ground state measured by ultrasonic sound velocity dispersion ${ }^{7}$ and in crossed molecular beam experiments. ${ }^{8}$ Theoretical calculations using ab initio potential energy surfaces show, however, a significant increase of the rotational energy transfer rates in $\mathrm{H}_{2}-\mathrm{He}$ collisions if one compares $\mathrm{H}_{2}(v=0)$ and $\mathrm{H}_{2}(v=1)$ molecules.

In a similar way the vibrational energy transfer from $\mathrm{H}_{2}(v=1)$ molecules can be studied. Figure 4 shows the time evolution of the HD 


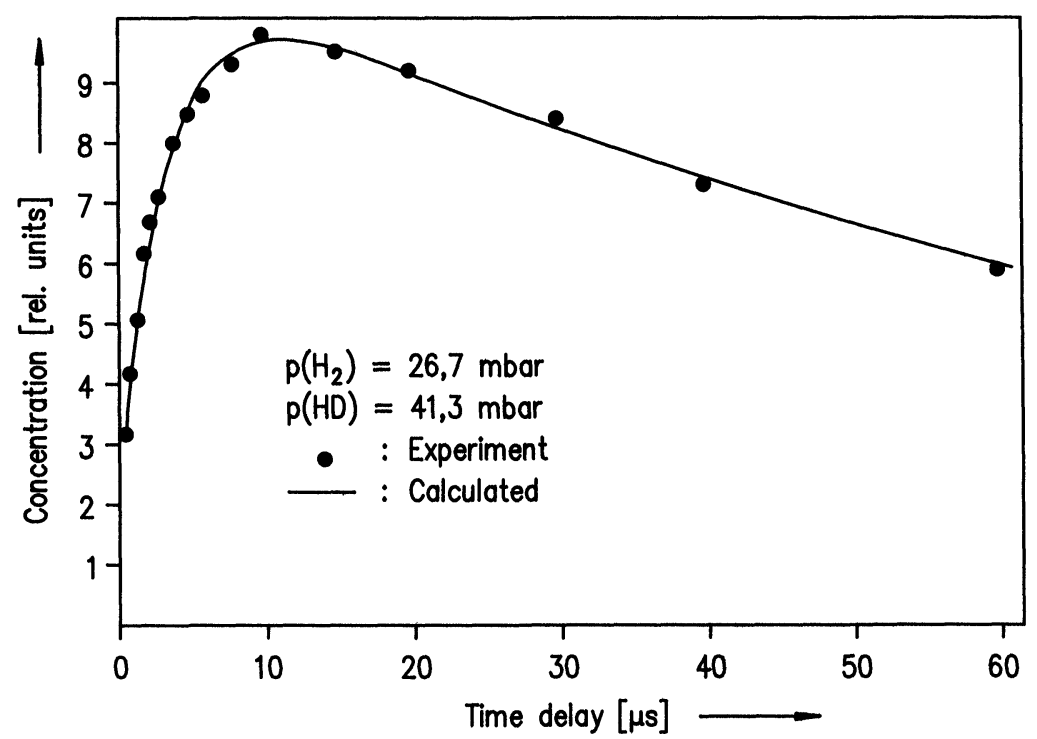

Figure 4 CARS signal of $\mathrm{HD}(v=1)$ formed in the vibrational energy transfer process from $\mathrm{H}_{2}(v=1)$.

$(v=1)$ concentrations induced by the energy transfer to HD $(v=0)$ from $\mathrm{H}_{2}(v=1)$ molecules.

The diffusion of excited $\mathrm{H}_{2}$ and $\mathrm{HD}$ out of the CARS beam strongly influences the time evolution of the CARS signal. To estimate the influence of diffusion, an analytical expression for the solution of the kinetic equations coupled with transport processes is required. From such modelling calculations the rate constants for the vibrational energy exchange processes

$$
\begin{aligned}
\mathrm{H}_{2}(v=1) & +\mathrm{HD}(v=0) \rightleftharpoons \mathrm{H}_{2}(v=0)+\mathrm{HD}(v=1) \\
& +\Delta \mathrm{E}=469.4 \mathrm{~cm}^{-1}
\end{aligned}
$$

of $1.9 \times 10^{-13} \mathrm{~cm}^{3} / \mathrm{s}$ in the exothermal and $1.4 \times 10^{-14} \mathrm{~cm}^{3} / \mathrm{s}$ in the endothermal direction are obtained. These rates are somewhat lower than previous theoretical estimations. ${ }^{10}$

\section{REACTIVE AND INELASTIC CHANNELS IN THE REACTIONS OF ATOMS WITH VIBRATIONALLY EXCITED MOLECULES}

The simplest systems in which the specific effect of a selective vibrational excitation can be studied are those of reactions of free atoms 


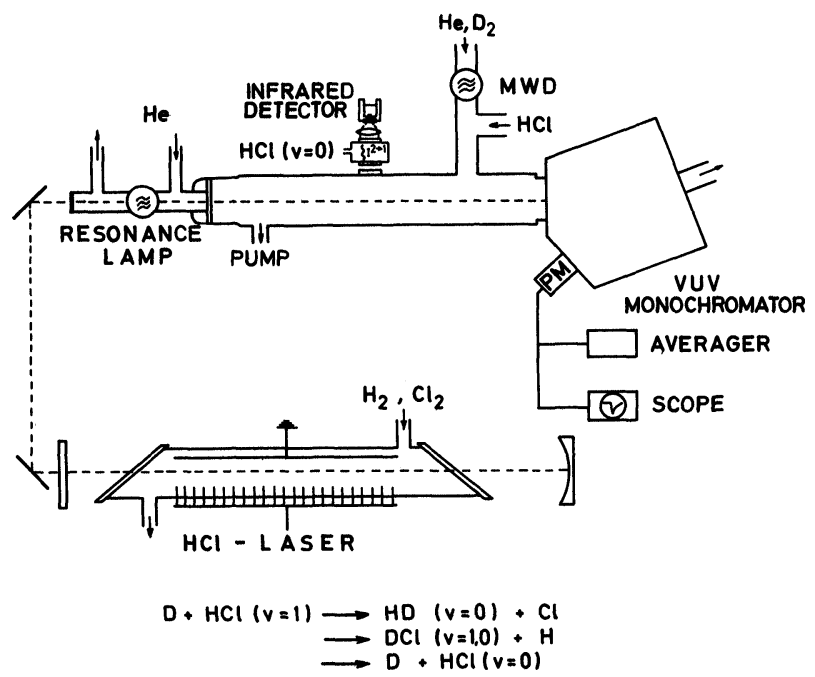

Figure 5 Discharge-flow system for simultaneous time-resolved detection of the concentration of reacting atoms and vibrationally excited $\mathrm{HCl}(v)$ molecules.

with vibrationally excited diatomic molecules. The various channels for removal of the vibrationally excited molecules $\mathrm{BC}(v)$ may be written as

$$
\mathrm{A}+\mathrm{BC}(v) \longrightarrow \begin{aligned}
& \mathrm{A}+\mathrm{BC}\left(v^{\prime}\right) \\
& \mathrm{AB}\left(v^{\prime}\right)+\mathrm{C} \\
& \mathrm{AC}\left(v^{\prime}\right)+\mathrm{B} \\
& (\mathrm{ABC})^{*}+\mathrm{M}
\end{aligned} \quad \Delta \mathrm{H}^{0} \gtrless 0
$$

As model systems for the competition between energy transfer processes and chemical reactions under non-equilibrium conditions one can use simple thermoneutral halogen atom exchange reactions. Vibrationally excited $\mathrm{HCl}(v)$ molecules can be consumed by $\mathrm{H}$ or $\mathrm{D}$ atoms in electronically adiabatic processes either by thermoneutral hydrogen atom exchange, the slightly exothermic hydrogen atom abstraction reaction, or in non-reactive collisions. Figure 5 shows an experimental arrangement for the observation of these elementary processes. $\mathrm{HCl}$ molecules in the vibrational ground state are mixed with atoms in a discharge flow reactor. The decay of laser excited $\mathrm{HCl}$ $(v)$ is followed by infrared fluorescence. To distinguish between 
reactive and inelastic pathways, it is necessary to measure the absolute consumption of reactants and formation of products. This is achieved here by measuring the absolute concentration of the vibrational excited molecules using the rapid equilibration between the $\mathrm{HCl}(v)$ vibrational levels and a measurement of the relative population in the levels $v=1$ and $v=2$ as a function of time. The concentrations of the reacting atoms are followed by time-resolved atomic resonance absorption. Figure 6 summarizes the results for the $\mathrm{D}+\mathrm{HCl}(v=1)$ system. The non-reactive relaxation and not the hydrogen atom exchange or abstraction reaction is mainly responsible for the high $\mathrm{HCl}$ $(v=1)$ deactivation rate in contrast to predictions from theoretical calculations using semiempirical ${ }^{12}$ as well as ab initio potential energy surfaces. ${ }^{13}$ Further informations on this system can be obtained from experiments using translationally hot $\mathrm{H}$ and $\mathrm{D}$ atoms to study the individual roles of inelastic excitations and reactive atom exchange processes. It is found that the reactive exchange process has a generally lower efficiency than the $\mathrm{T}-\mathrm{V}$ process. In the case of $\mathrm{HCl}$, however, the degree of vibrational excitation in the reactive channel is higher. It appears that once the system is following the potential energy surface for reactive exchange and has entered the transition state for reaction, the deposition of energy into higher vibrational states is much more facile. However, the system does not enter the reactive surface as readily perhaps because of some geometrical constraints to overcome the reactive barrier. ${ }^{14} \mathrm{~A}$ detailed of experi-

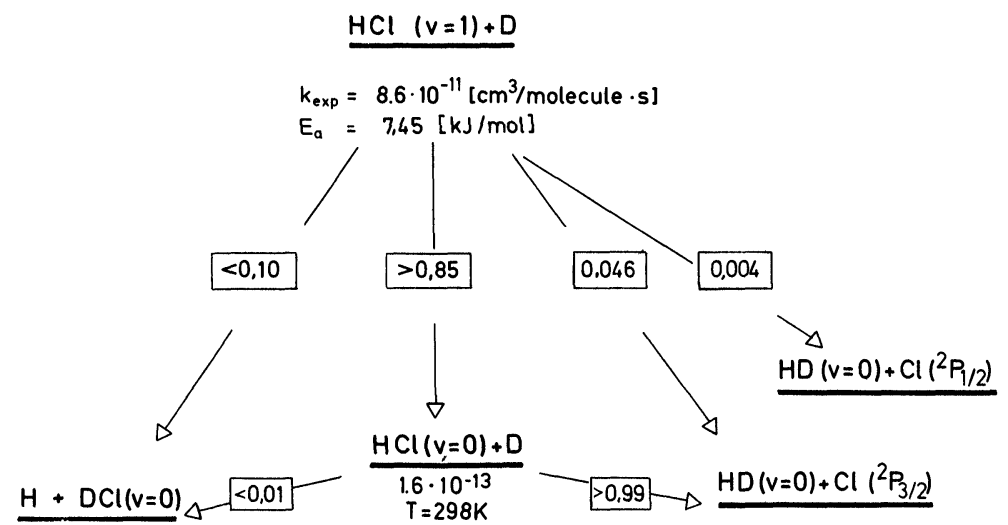

Figure 6 Experimental results for different channels in the $\mathrm{D}+\mathrm{HCl}(v=0,1)$ reaction. 


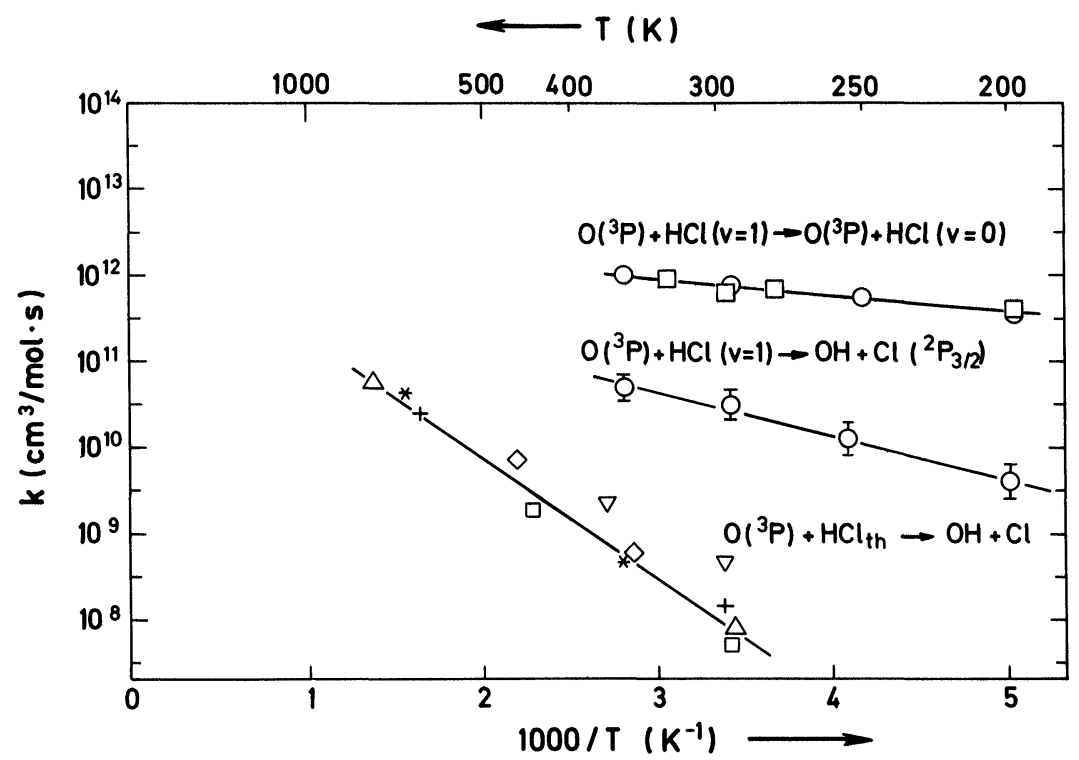

Figure 7 Experimental data for the temperature dependence of the rates for vibrational relaxation and reaction of $\mathrm{HCl}(v=1,0)$ with $\mathrm{O}\left({ }^{3} \mathrm{P}\right)$ atoms.

mental and theoretical results in the $\mathrm{H}(\mathrm{D})+\mathrm{H}(\mathrm{D})-\mathrm{Cl}$ system is given in. ${ }^{15}$

Ground state oxygen atoms react relatively slowly with thermal $\mathrm{HCl}$ at room temperature. The rate and Arrhenius activation energy of the reaction has been measured directly by several methods. These measurements show that a single vibrational quantum excitation can deliver enough energy for overcoming the potential energy barrier of the reaction. When $\mathrm{HCl}(v=1)$ molecules are generated in the flow system by absorption of the laser pulse, the decay of $\mathrm{HCl}(v=1)$ is significantly accelerated in the presence of oxygen atoms. However, the data given in Figure 7 indicates that the reactive channel to form $\mathrm{OH}+\mathrm{Cl}$ gives only a small contribution to the rapid removal of $\mathrm{HCl}$ $(v=1)$ by $\mathrm{O}\left({ }^{3} \mathrm{P}\right)$. The rate enhancement is much less than the factor $\exp \left(\mathrm{E}_{\mathrm{v}}(v=1) / \mathrm{RT}\right)$. Since the Arrhenius pre-exponential factor is not changed significantly by vibrational excitation, the contribution of $\mathrm{HCl}$ $(v=1)$ molecules to the thermal reaction is small for most temperatures of interest. At $200 \mathrm{~K}$ thermal excited $\mathrm{HCl}(v=1)$ molecules contribute less than $10^{-3} \%$ and at $2000 \mathrm{~K}$ about $10 \%$ to the total 
consumption of $\mathrm{HCl}$ by $\mathrm{O}\left({ }^{3} \mathrm{P}\right)$ atoms. As shown by quasiclassical trajectory calculations, the remaining thermal activation energies for $\mathrm{HCl}(v=1,2)$ are very similar. ${ }^{16} \mathrm{~A}$ theoretical model to explain the effective energy transfer in collisions involving P-state atoms as a result of electronically nonadiabatic curve crossing was given by Nikitin and Umanski. ${ }^{17}$ As shown in Figure 8, several potential energy surfaces exist for the interaction of $\mathrm{O}\left({ }^{3} \mathrm{P}\right)$ atoms with $\mathrm{HCl}(v)$. At certain distances a nonadiabatic coupling between the different vibronic states is possible. The approach of the reactants $\mathrm{O}\left({ }^{3} \mathrm{P}\right)$ and $\mathrm{HCl}$ on a triplet surface followed by a nonadiabatic transition to the singlet $\mathrm{HOCl}$ surface as an intermediate complex has been discussed as the possible origin of the potential energy barrier in this reaction. However, the fact that this crossing point appears to be necessarily lower than the saddle point of the lowest triplet surface is of course an artifact of the single coordinate correlation diagram. The experimental results on the reverse $\mathrm{Cl}+\mathrm{OH}(v \leq 9)$ reaction ${ }^{18}$ and the observed formation of $\mathrm{OH}(v=1)$ from $\mathrm{O}\left({ }^{3} \mathrm{P}\right)+\mathrm{HCl}(v=2)^{19}$ indicate that the chemical reaction occurs predominantly vibronic adiabatically on a triplet sur-

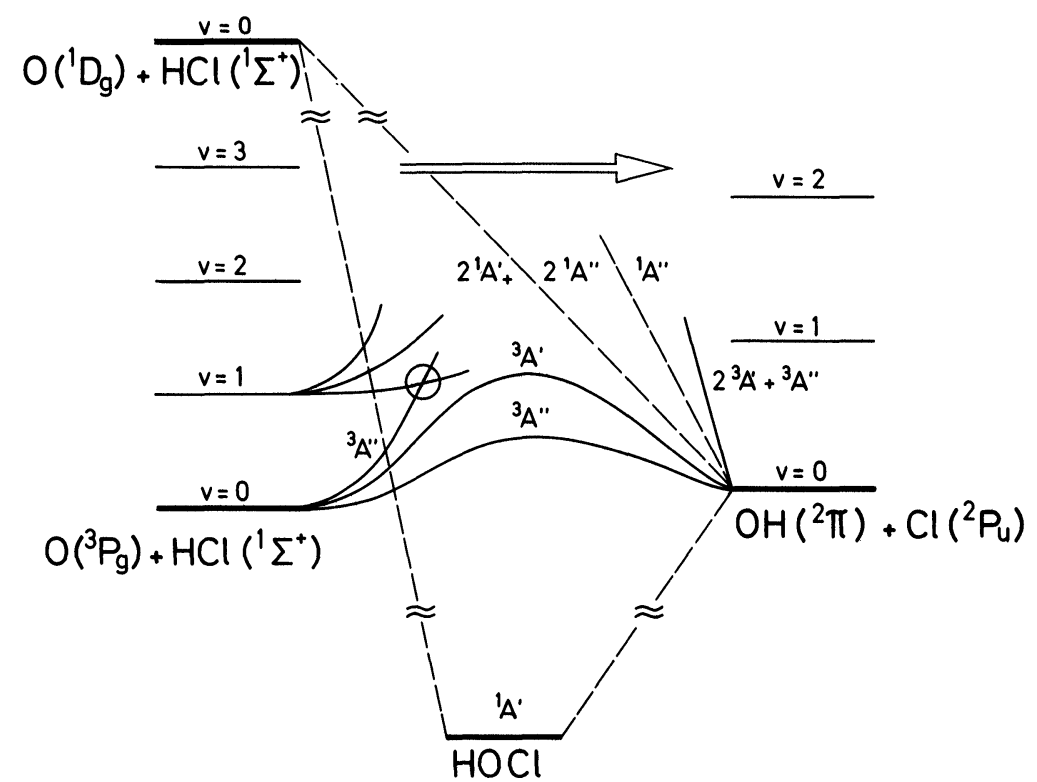

Figure 8 Chemical reaction and vibrational deactivation of $\mathrm{HCl}(v)$ in collisions with $\mathrm{O}$ $\left({ }^{3} \mathrm{P}\right)$ atoms. 
face and does not proceed through a long-living $\mathrm{HOCl}$ complex. However, such interpretation of the experimental results on the competition of reactive and inelastic channels in the reactions of vibrationally excited $\mathrm{HCl}$ molecules are still qualitative. More quantitative ab initio calculations including electronic nonadiabatic processes should be carried out for these systems.

On the other hand the reaction between a hydrogen atom and a hydrogen molecule provides the simplest system which has been studied now theoretically for more than half a century. ${ }^{20}$ As shown in Figure 9 single quantum vibrational excitation of the $\mathrm{H}_{2}$ molecule exceeds the Arrhenius activation energy $\left(E_{a}\right)$ the threshold energy $\left(E_{0}\right)$ as well as the classical barrier height $\left(E_{c}\right)$ of the reaction $D+\mathrm{H}_{2}$. A CARS detection system provides an ideal method for monitoring directly reactants and products in the $\mathrm{D}+\mathrm{H}_{2}(v=1)$ reaction. The reaction is followed in a discharge flow system, where the atoms and $\mathrm{H}_{2}$ $(v=1)$ molecules were generated by microwave discharges. ${ }^{21}$ As shown in Figure 10, $\mathrm{HD}(v=1)$ and $\mathrm{HD}(v=0)$ molecules are formed in adiabatic and non-adiabatic reaction pathways. Information on the competition of reactive and inelastic channels can be obtained by monitoring the decrease of $\mathrm{H}_{2}(v=1)$ in the presence of $\mathrm{D}$ atoms (see Figure 11) corrected for the energy transfer process $\mathrm{HD}(v=1)+\mathbf{H}_{2}$ $(v=0) \rightarrow \mathrm{HD}(v=0)+\mathrm{H}_{2}(v=1)$ described above. The experimen-

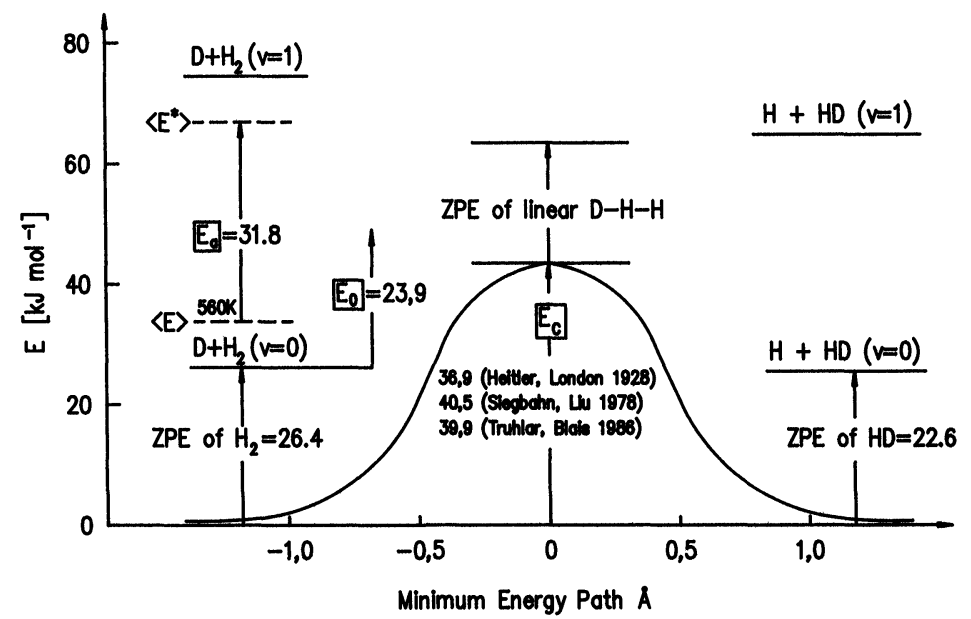

Figure 9 Characteristic energies for the $\mathrm{D}+\mathrm{H}_{2}(v=0,1)$ reaction. 


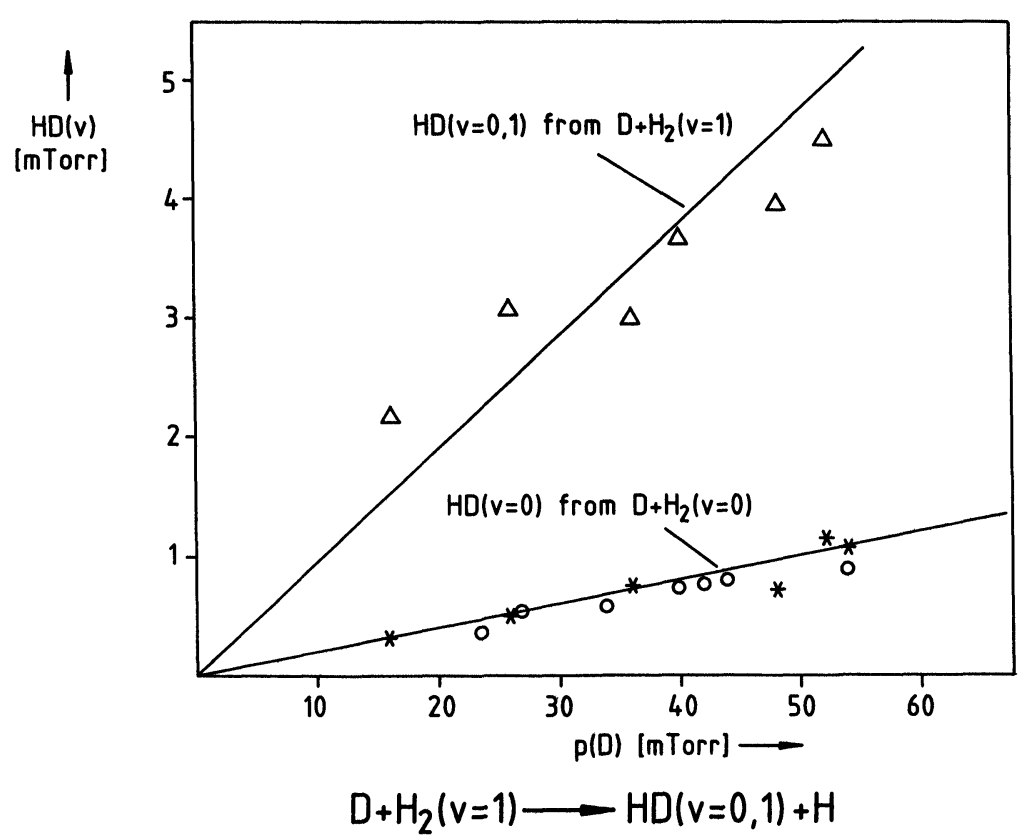

Figure 10 CARS-signals of $\mathrm{HD}(v=0,1)$ formed in the $\mathrm{D}+\mathrm{H}_{2}(v=1)$ reaction.

tal results obtained so far indicate about equal importance of inelastic and reactive channels as well as a predominance of adiabatic over non-adiabatic reactive channels. As shown in Figure 12, these experimental results are in good agreement with the predictions of quasiclassical trajectory, ${ }^{22}$ semiclassical variational transition state ${ }^{23}$ and approximate quantum calculations with the Fixed Angle Reactor Model (FARM) ${ }^{24}$ using the ab initio LSTH surface ${ }^{25}$ or a new surface based on double-many-body-expansions (DMBE) ${ }^{23}$ The new DMBE surface has a lower classical barrier of $9.65 \mathrm{kcal} / \mathrm{mol}$ compared to $9.80 \mathrm{kcal} / \mathrm{mol}$ of the LSTH surface. However, the calculated rate constants for reactions of vibrationally excited hydrogen molecules are somewhat lower than previous results, in agreement with the experimental data. In some respects, this agreement with quasiclassical trajectories is surprising since the reaction of $\mathrm{H}_{2}(v=1)$ involves only a small number of state-to-state processes. Similarly good agreement has been obtained between predictions of quasi-classical trajectory calculations and experimental results using translationally hot $\mathrm{H}$ and $\mathrm{D}$ 


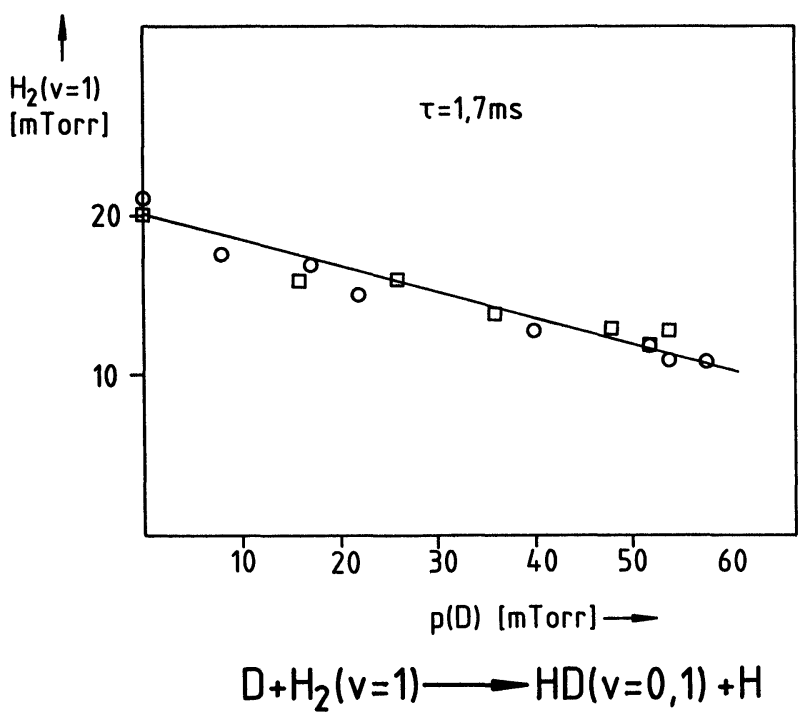

Figure 11 Relative decrease of the $\mathrm{H}_{2}(v=1)$ concentration in the $\mathrm{D}+\mathrm{H}_{2}(v=1)$ reaction as function of the $\mathrm{D}$-atom partial pressure.

atoms with CARS and REMPI detection of the reaction products ${ }^{26}$ or molecular beam scattering studies ${ }^{27}$ sampling also regimes of higher energy at the potential energy surface. As shown in Figure 12 pronounced quantum effects are expected at lower temperatures. ${ }^{28}$

\section{REACTIONS OF TRANSLATIONALLY HOT HYDROGEN ATOMS WITH OXYGEN MOLECULES}

Chemical reactions of fast ("hot") atoms for nuclear recoil and photolysis processes have long been investigated by analysis of their stable end products. On bombarding $\mathrm{Li}$ with neutrons, for example, tritium $\left({ }^{3} \mathrm{H}\right)$ atoms with a recoil energy of $2.7 \mathrm{MeV}$ are formed. Collisions then retard these fast ${ }^{3} \mathrm{H}$ atoms to the "chemical" energy range around $20 \mathrm{eV}$ to give a broad, continuous distribution of velocities. Thus the reaction energy cannot be controlled directly. Narrow-bandwidth laser light of high intensity and short pulse length $\left(10^{-8} \mathrm{~s}\right)$, on the other hand, allows high concentrations of atoms with defined velocities to be produced by photodissociation on a short time scale. As an example, the reaction of translationally excited hydrogen atoms $\mathrm{H}^{\mathrm{T}}$ with oxygen molecules is examined. 


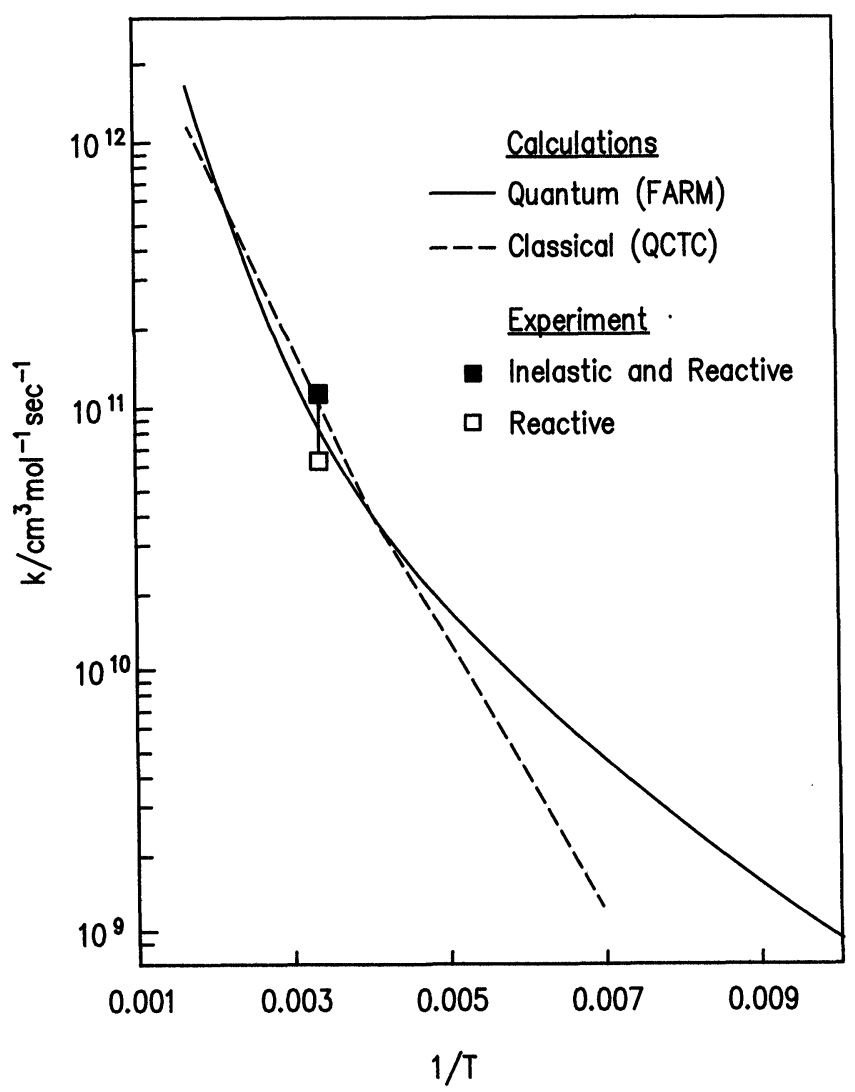

Figure 12 Comparison of theoretical predictions and CARS measurements of the rate constants for the $\mathrm{D}+\mathrm{H}_{2}(v=1)$ reaction.

Despite the large number of elementary reactions taking place in the oxidation of hydrocarbons, the important parameters of the combustion process are controlled by relatively few elementary reactions. Sensitivity analysis, shows that the important parameters such as flame velocity are controlled to large extent by the reaction of hydrogen atoms with oxygen molecules. ${ }^{29}$ This endothermic reaction leads to the formation of the two reactive radicals and is therefore the most important chain-branching step. As shown in Figure 13 the dynamics of such an elementary reaction with a high energy barrier can be studied in microscopic detail by combining translationally hot atom 


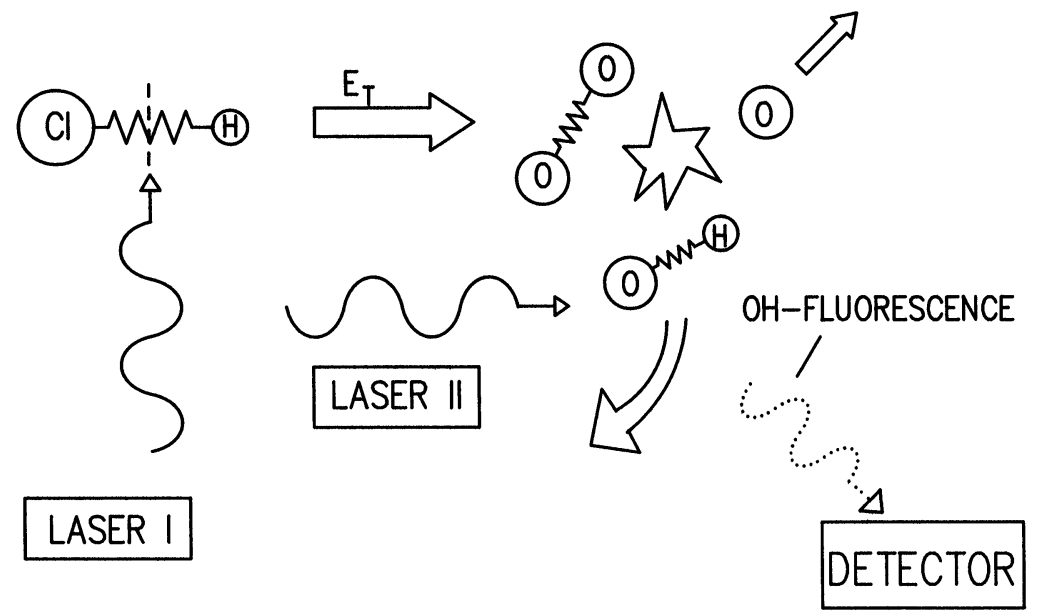

Figure 13 Production of fast hydrogen atoms by excimer laser photolysis and product detection by laser induced fluorescence.

formation by laser photolysis with time-, state- and orientationresolved product detection with laser induced fluorescence spectroscopy. The apparatus is shown in Figure 14. Two antiparallel laser beams are directed coaxially through a flow reactor equipped with a baffle system to reduce the scattered light from the laser photolysis pulse and from the dye laser analysis pulse. The dye laser operates with Rodamine 640 and a frequency doubling KDP crystal to generate a pulse in the 306-311 $\mathrm{nm}$ region to probe $\mathrm{OH}$ radicals by laser induced fluorescence. Fluorescence light is then detected as a function of the dye laser wavelength through emission optics and a filter transmitting between 240 and $390 \mathrm{~nm}$ and by a photomultiplier.

Figure 15 gives few examples of the $\mathrm{OH}$ nascent rotational state distributions at different collision energies. ${ }^{30}$ The major part of the relative translational energy of the reactants is converted into rotational energy of the product $\mathrm{OH}$ in agreement with the results of quasi-classical trajectory calculations. ${ }^{31}$

The observed rotational energy distributions give interesting microscopic details on the molecular dynamics of these elementary steps. Spin-orbit and orbital-rotation interactions in the $\mathrm{OH}$ radical cause fine structure splittings for each rotational level. Each of these fine structure levels can be probed by different rotational subbands. The two $\mathrm{OH}$ spin states ${ }^{2} \Pi_{1 / 2}$ and ${ }^{2} \Pi_{3 / 2}$ are, within experimental error, 


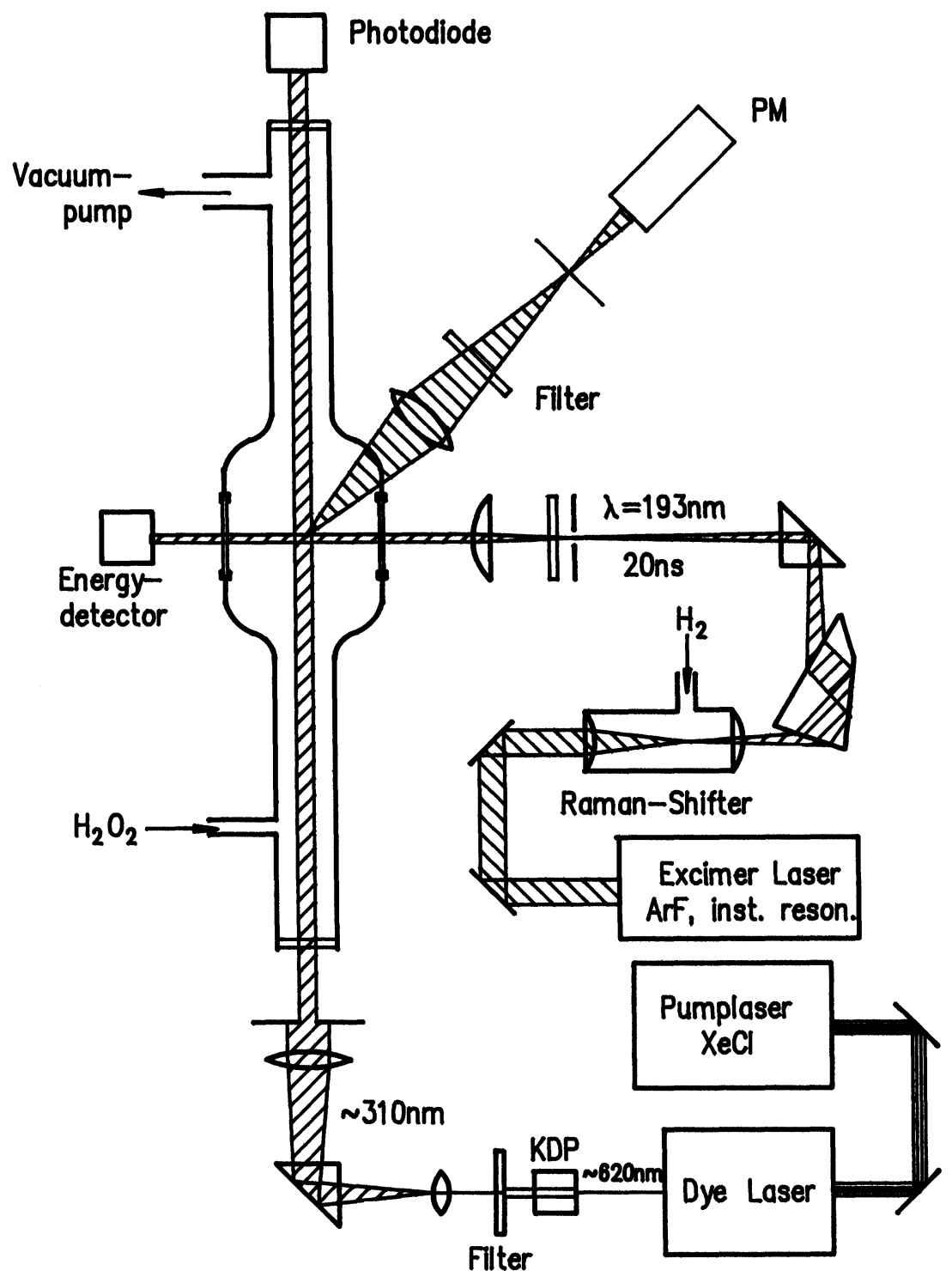

Figure 14 Experimental arrangement for the study of reactions with translationally hot atoms and radicals by combination of excimer laser photolysis and LIF product detection. 

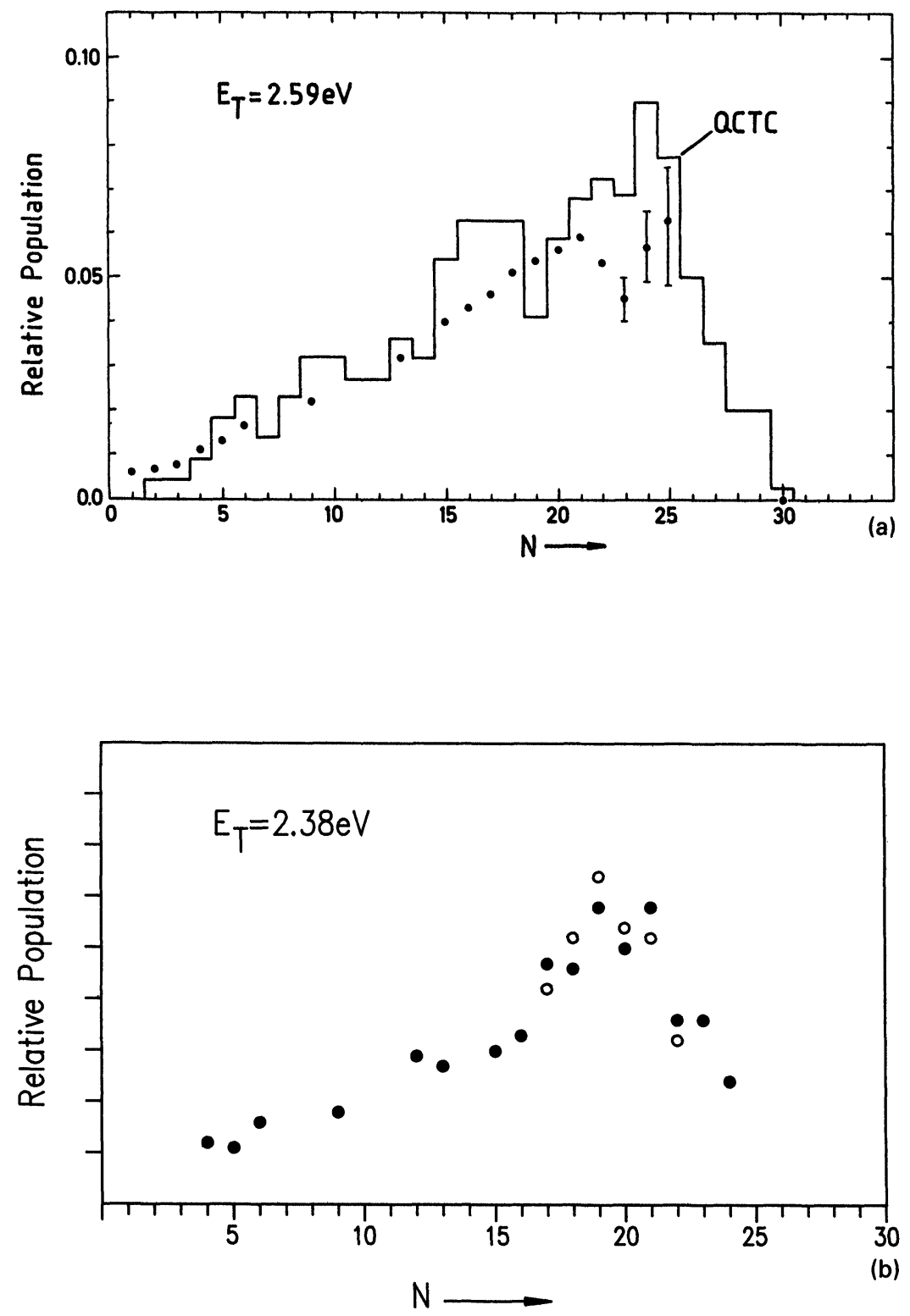

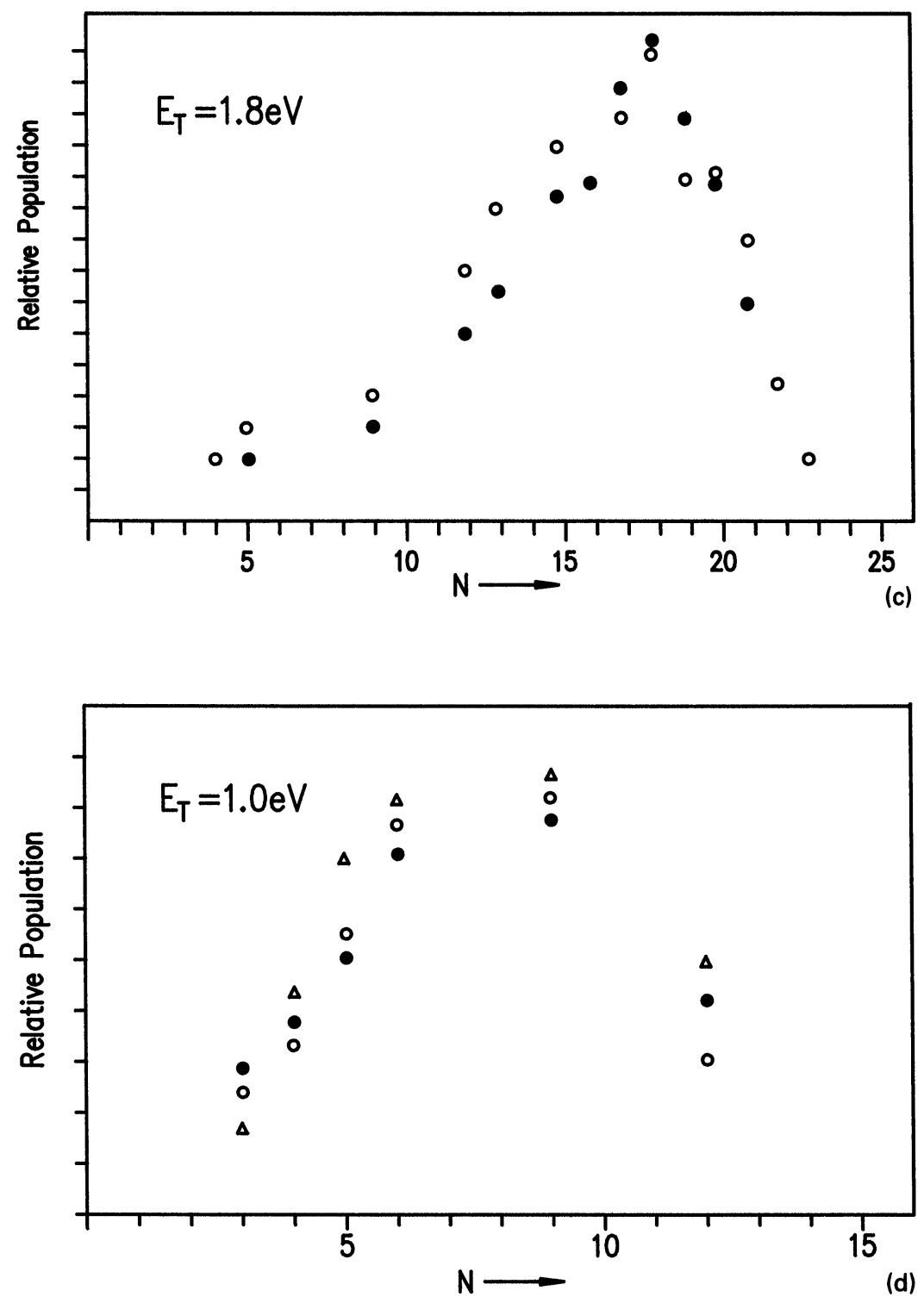

Figure 15 Nascent rotational state distribution of $\mathrm{OH}(v=0$ formed in the reaction $\mathrm{H}+\mathrm{O}_{2} \rightarrow \mathrm{OH}+\mathrm{O}$ at different collision energies. 
equally populated. However, as shown in Figure $17 \mathrm{a}$, the $\lambda$-doublet fine structure state show a clear preference for the lower-energy $\Pi^{+}$ $\left(\mathrm{A}^{\prime}\right)$ component. The experimental results show that breakup of the reaction complex generates forces in a plane containing the bond to be broken. The $\mathrm{OH}$ radical rotates in that plane and $\mathrm{J}_{\mathrm{OH}}$ is perpendicular to it and to the broken bond. This picture is consistent only with a preferential planar exit channel in these reactions. This could also be directly demonstrated by using polarized photolysis and analysis laser beams.

For experiments using polarized photolysis and analysis laser beams both lasers were linearly polarized (ca. $95 \%$ polarization) by using 10 Brewster quartz plates respectively (rack-polarizer). Both light beams are then directed through $\lambda / 2$ plates so that the electric vectors of both lasers can be adjusted independently to any desired angle. The polarization experiments are based on measuring the distribution of orientations of the $\mathrm{OH}$ angular momentum vector $\mathrm{J}$ by using the polarized dissociation and analysis laser. $\mathrm{OH}$ fluorescence intensity is observed with the electric vectors of both lasers $E_{D}$ and $E_{E}$ parallel and perpendicular to each other. Dissociation of $\mathrm{HBr}$ at $193 \mathrm{~nm}$ to $\mathrm{H}+\mathrm{Br}\left({ }^{2} \mathrm{P}_{3 / 2}\right)$ is induced by a perpendicular transition, so that the $\mathrm{H}$ atom flight direction is aligned with a $\sin ^{2}$-distribution along $E_{D}$, i.e. $v_{H} \perp E_{D}$ preferentially. Figure 16 shows the variation of the $\mathrm{OH}-\mathrm{Q}_{1} 16\left(v^{\prime \prime}=0\right)$ fluorescence intensity with polarization of the dissociation laser $E_{D}$ relative to analysis laser $E_{E}$. The observed preference $J_{O H} \| E_{D} \perp V_{H}$ can be explained by restriction in the possible reaction geometries at high collision energies. Trajectory calculations show that the $\mathrm{H}+\mathrm{O}_{2}$ reaction occurs essentially in a plane at high collision energies. ${ }^{31}$ From that we expect $\mathrm{J}_{\mathrm{OH}} \perp v_{\mathrm{H}}$ for randomly oriented $\mathrm{O}_{2}$ molecules. The transition moment $\mu_{\mathrm{E}}$ of Q-lines ${ }^{26}$ is perpendicular to the $\mathrm{OH}$ rotation plane $\left(\| \mathrm{J}_{\mathrm{OH}}\right)$ for high $\mathrm{OH}$ rotational states. Thus we get maximum $\mathrm{OH}$ excitation probability $\left|\mathrm{E}_{\mathrm{E}} \times \mu_{\mathrm{E}}\right|^{2}$ for $\mu_{\mathrm{O}}\left\|\mathrm{E}_{\mathrm{E}}\right\| \mathrm{J}_{\mathrm{OH}} \perp v_{\mathrm{H}}$ resulting in higher fluorescence intensity for $E_{E} \| E_{D}$ than for $E_{E} \perp E_{D} \cdot{ }^{32}$ This is also confirmed by analyzing the $\lambda$-doublet excitation of the $\mathrm{OH}$ radicals. The physical difference between the two $\lambda$-doublet components $\Pi^{+}\left(\mathrm{A}^{\prime}\right)$ and $\Pi^{-}\left(\mathrm{A}^{\prime \prime}\right)$ arises from interaction of the electronic spin-orbit momentum with the rotation of the molecule. For fast rotation of the $\mathrm{OH}$ radical, the unpaired electron in the $p$ orbital of the oxygen is no longer able to follow the movement of the atomic nuclei. If the $p$ orbital lies in the $\mathrm{OH}$ rotational plane, the electron distribution 


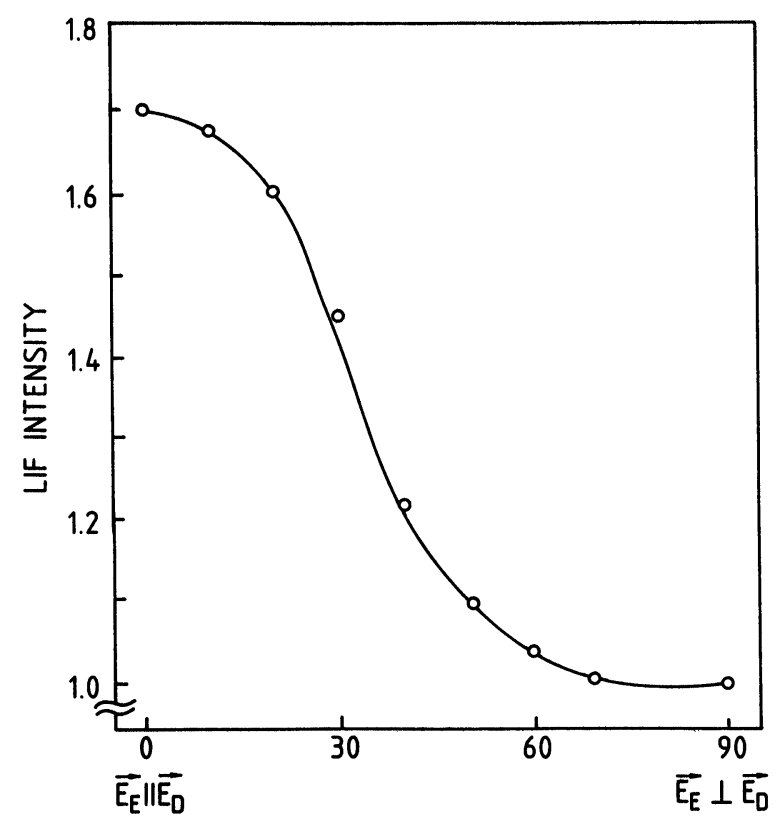

Figure 16 Variation of the $\mathrm{OH}-\mathrm{Q}_{1} 16\left(v^{\prime \prime}=0\right)$ fluorescence intensity from the reaction $\mathrm{H}+\mathrm{O}_{2} \rightarrow \mathrm{OH}+\mathrm{O}$ with polarization of the dissociation laser $\mathrm{E}_{\mathrm{D}}$ relative to the analysis laser $\mathrm{E}_{\mathrm{E}}$.

on the oxygen atom changes, becoming increasingly spherical. In contrast, for a $\Pi^{-}\left(\mathrm{A}^{\prime \prime}\right)$ configuration, the oxygen atom moves in the nodal plane of the $p$ orbital and thus continuous to "see" a dumbbellshaped electron environment, even for fast rotation. This leads to a splitting of the energies of the $\Pi^{+}\left(\mathrm{A}^{\prime}\right)$ and $\Pi^{-}\left(\mathrm{A}^{\prime \prime}\right)$ configurations, which selectively increases with increasing rotational energy. ${ }^{33}$ As shown in Figure 17a at $1.0 \mathrm{eV}$ collision energy, three $\mathrm{OH}$ radicals were found in the $\Pi^{+}\left(\mathrm{A}^{\prime \prime}\right)$ state for each $\mathrm{OH}$ radical in the $\Pi^{-}\left(\mathrm{A}^{\prime \prime}\right)$ state. This shows that the unpaired electron formed after bond cleavage of $\mathrm{O}_{2}$ stays in an orbital in the rotational plane of the $\mathrm{OH}$ radical. During the reaction, most of the $\mathrm{HO}_{2}$ complexes do not rotate out of the initial plane, because of the short reaction time at high collision energies (see Figure 17b). The reaction $\mathrm{H}+\mathrm{O}_{2}$ is known to take place adiabatically on the ground-state potential surface of the $\mathrm{HO}_{2}\left({ }^{2} \mathrm{~A}^{\prime \prime}\right)$ radical. Experimentally a total reaction cross-section of $0.42 \pm 0.2 \AA^{2}$ at $\mathrm{E}=2.6 \mathrm{eV}$ 


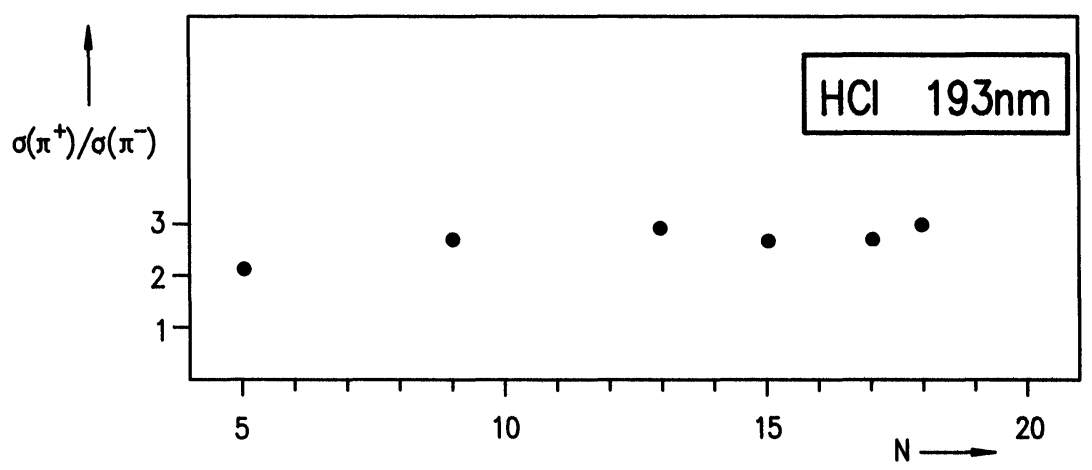

Partitioning into the $\mathrm{OH} \lambda$-doublet components for the reaction $\mathrm{H}_{2} \mathrm{O}_{2}-\mathrm{OH}+\mathrm{O}$ at collision energy of $43 \mathrm{kcal} / \mathrm{mol}$
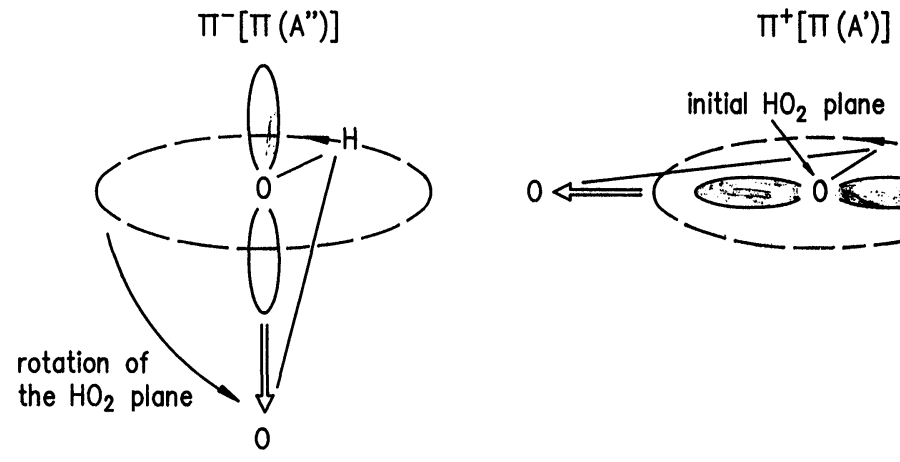

$$
\mathrm{H}+\mathrm{O}_{2} \longrightarrow \mathrm{OH}+\mathrm{O}
$$

nonplanar reaction pathway

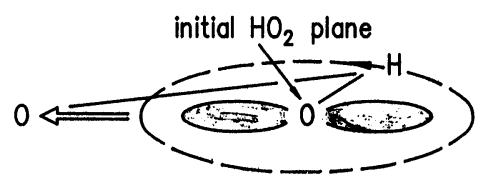

Figure 17 Vector properties of the $\mathrm{H}+\mathrm{O}_{2} \rightarrow \mathrm{OH}+\mathrm{O}$ reaction.

is found.$^{34}$ The theoretical reactive cross-section obtained under these conditions by quasi-classical trajectory calculations ${ }^{31,35}$ on the MeliusBlint $^{36}$ surface is $0.38 \AA^{2}$. These numbers cannot be compared directly, because the multiplicity of the ${ }^{2} \mathrm{~A}^{\prime \prime}$ surface of $\mathrm{HO}_{2}$ is not taken into account. The observed discrepancies may be attributed to a 
reduction of calculated reaction cross-section due to a "rigid" character and a barrier of $8 \mathrm{KJ} \mathrm{mol}^{-1}$ in the Melius-Blint surface for dissociation of the $\mathrm{HO}_{2}$ in the reaction $\mathrm{HO}_{2}+\mathrm{M} \rightarrow \mathrm{H}+\mathrm{O}_{2}+\mathrm{M}^{37}$ Later calculations ${ }^{38,39}$ reduce this barrier. Also for the reaction $(-1)$ $\mathrm{O}+\mathrm{OH} \rightarrow \mathrm{O}+\mathrm{H}$ the Melius-Blint surface apparently overestimates the long-range $\mathrm{O}-\mathrm{OH}$ attraction, while the Quack-Troe interpolation scheme ${ }^{37}$ leads to better agreement with the experimental values at low temperature if the two lowest electronic states of the $\mathrm{HO}_{2}$ radical are taken into account. Calculated rate coefficients obtained by using this theoretical cross sections from the surface ${ }^{36}$ are in agreement with shock tube measurements for $k_{1}$ by Schott. ${ }^{40}$ However, as shown in Figure 5, recent shock tube experiments ${ }^{41,42}$ using time-resolved atomic resonance line absorption give higher values for $k_{1}$ in agreement with the reactive cross sections obtained in state selected experiments. ${ }^{34}$ This example shows that even for a very simple radical reaction in combustion more work has to be done on the potential energy surface to obtain a satisfactory agreement between the results from quantum chemistry and state selective and thermal experiments.

\section{References}

1. M. Bodenstein, Z. Phys. Chem. 85, 329 (1913).

2. W. Nernst, Z. Elektrochem. 22, 62 (1916).

3. U. Buck, F. Huisken, A. Kohlhase and D. Otten, J. Chem. Phys. 78, 4439 (1983).

4. J. Arnold, D. Chandler and Th. Dreier, J. Chem. Phys. (to be published).

5. B. Raffel, J. Warnatz, H. Wolff, J. Wolfrum and R. J. Kee, Progr. in Astronautics and Aeronautics, Vol. 105 (1986); U. Maas and J. Warnatz, Proc. of the 11th ICDERS Conference, Warshau (1987).

6. W. Meier, G. Ahlers and H. Zacharias, J. Chem. Phys. 85, 2599 (1986).

7. L. M. Valley and R. C. Amme, J. Chem. Phys. 50, 3190 (1969).

8. U. Beck, H. Meyer and R. J. LeRoy, J. Chem. Phys. 80, 5589 (1984).

9. P. McGuire, J. Chem. Phys. 62, 525 (1975).

10. E. E. Nikitin, Theory of Elementary Atomic and Molecular Processes in Gases, Clarendon, Oxford (1974); R. J. Pirkle and T. A. Cool, Chem. Phys. Lett. 42, 58 (1976).

11. D. Arnoldi and J. Wolfrum, Ber. Bunsenges. Phys. Chem. 80, 892 (1976).

12. R. E. Weston, Jr., J. Phys. Chem. 83, 61 (1979); J. C. Miller and R. J. Gordon, J. Chem. Phys. 78, 3713 (1983) and references therein.

13. P. Botschwina and W. Meyer, Chem. Phys. 20, 43 (1977); A. F. Voter and W. A. Godard III, J. Chem. Phys. 75, 3638 (1981).

14. C. A. Wight, F. Magnotta and S. R. Leone, J. Chem. Phys. 81, 3951 (1984).

15. J. Wolfrum, "Reactions of vibrationally excited molecules" in Reactions of Small Transient Species, p. 105-156 (A. Fontijn and M. A. A. Clyne Eds.), Academic Press, London (1983). 
16. R. D. H. Brown and I. W. M. Smith, Int. J. Chem. Kinet. 10, 1 (1978); A. Persky and M. Broida, J. Chem. Phys. 81, 4352 (1984).

17. E. E. Nikitin and S. Y. Umanski, Faraday Discuss. Chem. Soc. 53, 1 (1972).

18. B. A. Blackwell, J. C. Polanyi and I. I. Sloan, Chem. Phys. 24, 25 (1977).

19. R. D. MacDonald and C. B. Moore, J. Chem. Phys. 68, 513 (1978).

20. J. Wolfrum, J. Phys. Chem. 90, 375 (1986).

21. Th. Dreier and J. Wolfrum, Int. J. Chem. Kinet. 18, 919 (1986); J. Wolfrum, Disc. Faraday Soc. 84 (1987).

22. H. R. Mayne and J. P. Toennies, J. Chem. Phys. 75, 179 (1981); N. C. Blais and D. G. Truhlar, Chem. Phys. Lett. 102, 120 (1983).

23. B. C. Garrett, D. G. Truhlar, A. J. C. Varandas and N. C. Blais, Int. J. Chem. Kinet. 18, 1065 (1986).

24. B. M. D. D. Jansen op de Haar and G. G. Balint-Kurti, J. Chem. Phys. 85, 2614 (1986).

25. B. Liu, J. Chem. Phys. 58, 1925 (1973); 80, 581 (1984); P. Siegbahn and B. Liu, J. Chem. Phys. 68, 2457 (1978); D. G. Truhlar and C. J. Horrowitz, J. Chem. Phys. 68, 2466 (1978); 71, 1514 (1979).

26. E. E. Marinero, C. T. Rettner and R. N. Zare, J. Chem. Phys. 80, 4142 (1984); J. J. Valentini and D. P. Gerrity, Int. J. Chem. Kinet. 18, 937 (1986).

27. R. Götting, J. P. Toennies and M. Vodegel, Int. J. Chem. Kinet. 18, 949 (1986); R. Götting and H. R. Mayne, J. Chem. Phys. 85, 6396 (1986); R. Götting, V. Herrero, J. P. Toennies and M. Vodegel, Chem. Phys. Lett. 137, 524 (1987).

28. G. G. Balint-Kurti, Faraday Discussion, 84 (1987).

29. J. Wolfrum, 20th Symp. (Int.) on Combustion p. 559, The Combustion Institute, Pittsburgh (1984).

30. E. Linnebach and K. Kleinermanns (to be published).

31. K. Kleinermanns and R. Schinke, J. Chem. Phys. 80, 1440 (1984).

32. K. Kleinermanns and E. Linnebach, Appl. Phys. B, 36, 203 (1985).

33. M. P. Sinka, C. D. Caldwell and R. N. Zare, J. Chem. Phys. 61, 491 (1974).

34. K. Kleinermanns and J. Wolfrum, J. Chem. Phys. 80, 1446 (1984); E. Linnebach and $\mathrm{K}$. Kleinermanns (to be published).

35. J. A. Miller, J. Chem. Phys. 74, 5120 (1981).

36. C. F. Melius and R. J. Blint, Chem. Phys. Lett. 64, 183 (1979).

37. C. Cobos, H. Hippler and J. Troe, J. Phys. Chem. 89, 342 (1985); J. Troe, J. Phys. Chem. 90, 3485 (1986); J. Troe, Combust. Flame (1988; in press).

38. T. H. Dunning, Jr., S. P. Walch and M. M. Goodgame, J. Chem. Phys. 74, 3482 (1981); G. J. Vazquez, S. D. Peyerimhoff and R. J. Buenker, Chem. Phys. 99, 239 (1985).

39. A. J. C. Varandas, J. Brandas and L. A. M. Quintaly, J. Phys. Chem. (1988, in press).

40. G. L. Schott, Combust. Flame 21, 357 (1973).

41. Th. Just and P. Frank, Ber. Bunsenges. Phys. Chem. 89, 181 (1985).

42. A. N. Pirraglia, J. V. Michael, J. W. Sutherland and R. B. Klemm, J. Phys. Chem. (1988, in press). 